\title{
Vikram Sarabhai: his vision for the development of atomic energy in India
}

\author{
R. B. Grover ${ }^{1, *}$ and M. R. Srinivasan ${ }^{2}$ \\ ${ }^{1}$ Member, Atomic Energy Commission, and Homi Bhabha National Institute, Mumbai 400094 \\ ${ }^{2}$ Former Chairman, and Member, Atomic Energy Commission, Ootacamund 643002
}

\begin{abstract}
Vikram Sarabhai formulated an ambitious profile for the development of atomic energy in India. Despite challenges arising from denial of international cooperation for several decades, technologies envisioned in the profile have been developed and the Department of Atomic Energy is now working to implement the technologies with the objective of accelerating the growth of installed nuclear capacity in the country.
\end{abstract}

Keywords: Heavy water, fast reactors, nuclear fuel, radio-isotopes, reprocessing, thermal reactors.

'There are three unique families of 20th century India the Tagores, the Sarabhais and the Tyabjis', opines Ramachandra Guha ${ }^{1}$. Indians generally know about the Tagores; not many know about the contributions of others. Coming to the Sarabhais, they lived in Ahmedabad, which was a thriving business city even before Mumbai and Kolkata. Ambalal Sarabhai generated great wealth through banking and money lending, textiles and other industries. He sent his children abroad for studies and amongst them was Vikram, who went to Cambridge. While Vikram and his siblings imbibed western culture, they were encouraged to respect Indian roots and culture. They returned to India and set up various institutions, and these included Physical Research Laboratory (PRL) and Indian Institute of Management (IIM), both at Ahmedabad, set up by Vikram Sarabhai. Both these institutions became trend setters. PRL led to setting up of India's Space programme, and IIM to a series of similar institutions.

From PRL, Vikram Sarabhai moved to Mumbai in May 1966 to steer India's atomic energy and space programmes after the untimely demise of Homi Bhabha. It fell upon Sarabhai to implement the vision of Bhabha by formalizing the organization structure of the Department of Atomic Energy (DAE). Uranium Corporation of India Limited (UCIL) as well as Electronics Corporation of India Limited (ECIL) were incorporated as Public-Sector Enterprises in 1967. Power Projects Engineering Division, the forerunner of Nuclear Corporation of India Limited (NPCIL), was established in 1967. Nuclear Fuel Complex (NFC) was set up in 1968 with Sarabhai as the

*For correspondence. (e-mail: rbgrover@hbni.ac.in) first Chairman of its Board. An organization dedicated to build heavy water plants, named Heavy Water Projects, was established in 1969. It was later renamed as Heavy Water Board. Activity at Kolkata to set up a Variable Energy Cyclotron was started in 1969 by BARC. Reactor Research Centre, later renamed as Indira Gandhi Centre for Atomic Research (IGCAR), was set up at Kalpakkam, $80 \mathrm{~km}$ south of Madras (now Chennai) in 1971 with the objective of conducting broad-based academic and postacademic research directed towards the development of sodium-cooled Fast Breeder Reactor (FBR) technology. The first school run by the Atomic Energy Education Society started functioning in Anushakti Nagar, Mumbai in 1969.

Activities of DAE were expanding and Sarabhai was aware of the management issues involved in running a large diversified programme. Scientists and engineers including the second author, who interacted with him, recall his mature decision making and practical approach toward management. He set up a Programme Analysis Group in the Department to help in the process of policy formulation. This group was very active during his time, but subsequently had a turbulent history, and went through several mutations. The present Nuclear Control and Planning Wing is doing somewhat similar function.

A landmark initiative by Sarabhai was to organize a seminar in January 1970. The seminar attracted large participation (the second author was one of the participants), about 800 , from diverse organizations in India and about a dozen scientists from foreign countries. Subsequent to the seminar, in July 1970, DAE released 'Atomic energy and space research: a profile for the decade 1970-80,2. A press release issued by Sarabhai on 25 May 1970 provides a glimpse of his thinking about the programmes in both atomic energy and space ${ }^{3}$. Contours of the programme listed in the profile and the press release are more or less the same. Taking the list of programmes included in the press release as well as the profile as the starting point, this article analyses how far the country has been successful in achieving the vision of Vikram Sarabhai in the area of atomic energy. The programmes listed include expanding nuclear installed capacity based on thermal reactors, designing and constructing $500 \mathrm{MWe}$ Pressurized Heavy Water Reactors (PHWRs), completing Fast Breeder Test Reactor (FBTR), designing and 
constructing a $500 \mathrm{MWe}$ Prototype Fast Breeder Reactor (PFBR), augmenting heavy water production capacity, augmenting uranium mining, completing Nuclear Fuel Complex, developing uranium enrichment technology based on gas centrifuge process and promoting widespread application of radio-isotopes in food preservation, sterilization of medical products, medicine and research.

\section{Development of nuclear technologies by India}

When looked from the point of view of development of technologies, DAE has done a very good job. While details can be seen in numerous publications from units of DAE, in particular two recent special issues of journals Sadhana and Progress in Nuclear Energy, ${ }^{4,5}$, a brief summary follows.

\section{Thermal reactors}

Pressurized heavy water reactors (PHWRs) were chosen by India as the mainstay for the thermal reactor programme and units of DAE together with the Indian industry have mastered the PHWR technology. PHWRs are operating at Rawatbhata (Rajasthan), Kalpakkam (Tamil Nadu), Narora (UP), Kaiga (Karnataka), Kakrapar (Gujarat) and Tarapur (Maharashtra). After setting up TAPS-3 and -4 at Tarapur, there was slowdown in building PHWRs as there was a significant mismatch between demand and domestic supply of uranium. Even the operating PHWRs were running at very low capacity factors in the first decade of this century and capacity factors reached as low as $50 \%$ in 2008 . It was not possible to import uranium due to the then prevailing guidelines of the Nuclear Suppliers Group (NSG). A two-pronged strategy was developed by the Government of India: to intensify exploration in the country and open more uranium mines, and to launch a diplomatic initiative to resume international civil nuclear trade. Both initiatives have been successful. Domestic uranium production has increased and India is able to import uranium from the international market due to NSG adjusting its guidelines to facilitate international civil nuclear trade with India. Capacity factor of operating reactors started looking up from 2008 onwards (Table 1). Natural uranium is now available for setting up PHWRs and as a result, the Government first sanctioned construction of PHWRs at Rawatbhata (Rajasthan), Kakrapar (Gujarat) and Gorakhpur (Haryana) and subsequently ten units in fleet mode. Table 2 lists PHWRs under construction and already sanctioned. Additional sites have also been identified for construction of reactors. While Sarabhai had envisioned setting up of PHWRs of 500 MWe rating, units now being set up are of 700 MWe rating.

India started its nuclear power programme by setting up two Light Water Reactor (LWR) units at Tarapur on turn-key basis, and is now again setting up LWRs in addition to ongoing PHWR programme. Since modern LWRs have large rating, this will help India to quickly ramp up nuclear installed capacity, which is a necessity for deep decarbonization of the energy sector. Two VVER units, each $1000 \mathrm{MWe}$, set up in technical collaboration with Russia are already operating at Kudankulam (Tamil Nadu) and four more are under construction at the same site. It is envisaged to set up six more VVERs, of $1200 \mathrm{MWe}$ rating at a new site in technical collaboration with Russia.

Dialogue is ongoing with EDF, France to set up six EPRs, each $1650 \mathrm{MWe}$, at Jaitapur (Maharashtra), and with Westinghouse, USA to set up six APWRs, at Kovvada (Andhra Pradesh).

\section{Fast reactors}

India has been steadfast in pursuing a closed fuel cycle right from the inception of the atomic energy programme. A beginning toward pursuing a closed fuel cycle was made with the setting up of the first spent fuel reprocessing plant at Trombay and setting up of FBTR at Kalpakkam. India embarked on the construction of FBTR in collaboration with France, but had to go alone when

Table 1. Improvement in capacity factors of all Indian reactors over the past few years

\begin{tabular}{lcc}
\hline Year & Capacity factor $(\%)$ & Generation in million kW-hours \\
\hline $2008-09$ & 50 & 14,927 \\
$2009-10$ & 61 & 18,831 \\
$2010-11$ & 71 & 26,473 \\
$2011-12$ & 79 & 32,455 \\
$2012-13$ & 80 & 32,863 \\
$2013-14$ & 83 & 35,333 \\
$2014-15$ & 82 & 37,835 \\
$2015-16$ & 75 & 37,456 \\
$2016-17$ & 80 & 37,674 \\
$2017-18$ & 70 & 38,336 \\
$2018-19$ & 70 & 37,813 \\
\hline
\end{tabular}

Total installed capacity: 6780 MWe. 2008-09 means the year from 1 April 2008 to 31 March 2009. Low capacity factors for 2017-18 and 2018-19 are due to initial problems with power plant components at Kudankulam.

Table 2. PHWRs under construction, and approved for construction

\begin{tabular}{lcl}
\hline Location & No. of units & \multicolumn{1}{c}{ Status } \\
\hline Rawatbhata, Rajasthan & 2 & Under construction \\
Kakrapar, Gujarat & 2 & Under construction \\
Gorakhpur, Haryana & 4 & Approved \\
Mahi-Banswara, Rajasthan & 4 & Approved \\
Kaiga, Karnataka & 2 & Approved \\
Chutka, Madhya Pradesh & 2 & Approved \\
\hline
\end{tabular}

Unit size: $700 \mathrm{MWe}$. 
collaboration came to an end after India went in for a Peaceful Nuclear Explosion (PNE) in 1974. Original intent was to use MOX fuel with $30 \% \mathrm{PuO}_{2}$ and $70 \% \mathrm{UO}_{2}$ (with uranium enriched to $85 \%$ ) as the driver fuel. In view of non-availability of highly enriched uranium, a unique carbide fuel was developed and used in FBTR. This delayed first criticality of FBTR much beyond the original schedule, but made India confident of standing on its own.

Simultaneously, India embarked on design and development of a 500 MWe PFBR which was included in the profile. The work involved challenges which have been met by DAE and Indian industry. Construction at Kalpakkam has now been completed. PFBR is a pool type reactor with two primary loops, and two secondary loops with four steam generators per loop. The reactor is now under commissioning and being the first such reactor, the commissioning process is going on longer than normal. After PFBR has been commissioned and has run successfully for a while, commercial sodium-cooled fast breeder reactors will be launched and two such reactors will come close to the site of PFBR. A roadmap for further development of sodium-cooled fast reactors, including reactors having metallic fuel, has been prepared and is being pursued.

The profile acknowledges that production of plutonium for use in fast reactors was one of the considerations for launching of PHWR programme. The profile recognizes that development of technology for reprocessing of spent fuel to recover plutonium is a must to proceed further with the fast breeder reactor programme. India has indeed made rapid strides in developing and deploying reprocessing technology. Trombay facility reprocesses aluminium-clad spent fuel from research reactors. Plants at Tarapur and Kalpakkam process zircaloy-clad oxide fuels from PHWRs. To significantly increase reprocessing capability, an industrial scale Integrated Nuclear Recycle Plant (INRP) to reprocess PHWR fuel is under construction at Tarapur. Waste management facility has been integrated with this plant.

India has also set up an industrial scale demonstration plant at Tarapur for separation of minor actinides from spent fuel from thermal reactors.

Technology for reprocessing spent fuel from fast reactors, which is characterized by high burn-up, has also been developed and a facility for reprocessing, having capacity to reprocess spent fuel from PFBR and two more such reactors, is under construction at Kalpakkam close to the site of PFBR.

\section{Uranium mining and nuclear fuel fabrication}

Atomic Minerals Directorate for Exploration and Research, with its headquarters at Hyderabad and regional centres located in different parts of the country, is engaged in uranium exploration. For exploration of uranium, it employs latest technologies such as time domain electro-magnetic system along with gamma-ray spectrometer and magnetometer for airborne geophysical surveys, and multi-disciplinary field operations namely geological, geophysical, geo-chemical surveys, and drilling for obtaining rock samples.

India's uranium resources are not significant, and are of low grade. Despite low grade, India is exploiting whatever uranium resource is available and continuing exploration to locate further resources. As a result of its efforts, identified conventional uranium resources (Reasonably assured resources and inferred) are approaching 300,000 tonnes of $\mathrm{U}_{3} \mathrm{O}_{8}$. Two decades back this number was less than 100,000 tonnes. Apart from mines in Jaduguda region, mines have been opened up by UCIL at Tummalapalle in Andhra Pradesh. It is also planned to open mines in Meghalaya and Telangana.

Fuel is fabricated by NFC and it is meeting demands of continuously expanding nuclear power programme. Its products include fuel bundles for PHWRs and boiling water reactors (BWRs), sub-assemblies and hexagonal channels for FBR, core components for PHWR, square channels, cruciform rods and poison tubes for BWRs, zircaloy tubes and rods, stainless steel and special alloy grade tubes and pipes, steam generator and heat exchanger tubes for PHWR, high purity materials, etc. Apart from Hyderabad, it has facilities at Pazhayakayal (Tuticorin, Tamil Nadu) and is constructing a new facility at Rawatbhata (Rajasthan).

In addition, India has set up a facility for enrichment of uranium based on gas centrifuge process, the necessity for which was identified in the Profile.

\section{Heavy water production}

Research for developing technologies for producing heavy water was started in early nineteen-sixties. The first plant using electrolysis of water and liquid hydrogen distillation process was set up in Nangal in 1962. At present, six heavy water production plants are operating: two plants are based on $\mathrm{H}_{2} \mathrm{~S}-\mathrm{H}_{2} \mathrm{O}$ exchange process and the remaining use $\mathrm{NH}_{3}-\mathrm{H}_{2}$ exchange process. Since heavy water production process is energy intensive, special attention has been paid to reducing specific energy consumption. India is now the largest producer of heavy water and has sufficient heavy water in stock to feed upcoming PHWRs. Heavy water is also being exported.

\section{Applications of radio-isotopes}

Recognizing the contribution to economy and well-being of citizens of the applications of radiation and radioisotopes, the Profile calls for developing a plan for such applications. This in fact has been done by the Department 
and a separate organization, Board of Radiation and Isotope Technology (BRIT) was set up in 1989 and has been marketing radioisotopes, radiopharmaceuticals, radiation technology equipment, etc. BRIT works in close cooperation with BARC where radioisotopes are produced in research reactors. To meet growing need of radioisotopes and radiopharmaceuticals, additional research reactors are also planned.

Based on research done at BARC, several highyielding varieties of oilseeds and pulses have been produced and this is a continuing activity.

\section{Manpower training}

Recognizing the need for trained manpower, DAE has taken several initiatives, including setting up of Homi Bhabha National Institute (HBNI), an institute having the status of a deemed to be university, and getting Tata Institute of Fundamental Research recognized as a deemed to be university. Academic programmes being run at BARC Training School have now been accredited by HBNI. While the name Training School has been retained, it now runs as a Graduate School of a university. HBNI brings together academic programmes running at 11 institutions of DAE and programmes have seen significant expansion since the setting up of $\mathrm{HBNI}^{6}$. Nature index has ranked HBNI at 291st position amongst all academic institutions globally based on research output in science, gleaned from publications in 82 select science journals, during August 2018-July 2019.

In addition, NPCIL has set up training centers at its sites. The training centers are equipped to train engineers, supervisors, plant operators and maintenance technicians. Training includes facilitating licensing and qualification of the operation and maintenance personnel of the power stations. NPCIL has also developed and deployed full scope replica simulators for training control room personnel.

\section{Programme implementation and directions for the future}

Carrying forward the vision of Bhabha, Sarabhai formulated the Profile for the decade 1970-80 at a time when India was cooperating globally in nuclear science and engineering, and technology control regime applicable to nuclear arena had not yet evolved. This started changing with the Treaty on the Non-Proliferation of Nuclear Weapons (NPT) coming into force in March 1970, setting up of Zangger committee for implementation of export controls in accordance with Article III of NPT in 1971, and PNE by India in 1974. All international cooperation came to an abrupt halt, and slowed down India's progress in deployment of nuclear technology. NSG, an informal group of 'supplier' countries, also came into being after
1974 and gradual evolution of its guidelines made India's participation in international civil nuclear trade and cooperation even more difficult. Implementation of the programmes formulated by leaders of DAE had to factor in the changed international regime. DAE did continue with all programmes, but after 1974, it had to follow an autarchic path. Despite this adverse development, India has been able to develop technologies for building PHWRs including fuel fabrication, heavy water production, spent fuel reprocessing, waste management and other nuclear technologies on a broad front.

During initial years, besides design and development, construction of nuclear power plants was also a challenge as industry in India was going through a process of maturation. Many special materials, semi-finished items, rotating machinery, valves and instruments had to be imported for the reactors set up in the beginning of the programme. Engineers from the establishments of DAE worked in close cooperation with industry to realize manufacturing of complex equipment and components meeting stringent quality control requirements. Cooperation with DAE helped industry to expand expertise in detailed engineering, complex manufacturing processes and nondestructive testing techniques. Spillover of expertise to other industrial sectors has been of significant benefit to the growth of Indian economy. Expanded expertise and growth in size of the Indian industry (including public sector units) as well as establishments within DAE has given NPCIL confidence to envision and take up simultaneous construction of several reactors.

After having mastered PHWR technology, a twopronged approach indicated earlier with regard to getting access to more uranium was launched and is now showing results. Working together with Indian industry, NPCIL has to look at innovative ways to complete projects on time and within budget. Recent high-profile cases of project delays and cost overruns in nuclear industry in the West should be used to learn lessons to avoid their repeat in India. NPCIL did construct TAPS-3 and -4 on schedule and within the original budget. With regards to building PHWRs, India should set an ambitious target and collaborate with other public sector power companies to achieve the target.

India has also embarked upon building LWRs in technical collaboration with vendors in other countries. This will help ramping up nuclear installed capacity faster as LWRs have higher plant size. While doing so, NPCIL should absorb technology so that in due course of time, it can set up LWRs on its own as has been done by South Korea and China. Expertise acquired while building compact reactors for transport application should be leveraged to build large LWRs.

Economy of scale in nuclear power sector can be achieved either by increasing the unit size, or by building several units of small size. So far, nuclear industry has tried to achieve economy of scale by increasing the unit 
size. A section of leadership in nuclear industry in the West opines that economy of scale can also be achieved by building small and modular reactors (SMR), and building them in such a manner that fraction of work done in factories is maximized and that at site is minimized. Reduction in site work brings down gestation period and reduces cost as site work is expensive. For adopting this concept in India, detailed study is needed as relative cost of site work and factory work in India is not the same as in the West. Design of SMRs has to be so optimized that capital cost per MWe as well as land footprint per MWe is competitive when compared to large LWRs. Claims made about competitiveness of SMRs are based on feasibility studies and predicated on the assumption of large volumes. This would need confirmation by implementing projects.

PFBR is being commissioned and will provide valuable experience in building more such reactors. While negotiating for resumption of civil nuclear trade, it has been ensured that India has rights to reprocess imported fuel. As India sets up more reactors using imported uranium, it will be possible to use plutonium recovered from spent fuel to build more fast reactors.

In short, DAE has realized the objective of developing technologies as envisaged by the early leadership and now has to accelerate the ongoing implementation phase with a focus on cost optimization along with safety.

1. Guha, R., In conversation with Aparna Basu, IIC Quarterly, Summer 2019, pp. 66-76.

2. DAE, Atomic Energy and Space Research: A Profile for the Decade 1970-80, Bombay, 1970.

3. Sarabhai, V., Proposals for India's nuclear energy programme. Strategic Analysis, 2010, 34(2), 340-341.

4. Special issue on Nuclear Power Programme in India - Past, Present and Future. Sadhana, 2013, 38(5)

5. Special Issue on Development of Advanced Nuclear Technologies. Prog. Nucl. Energy, 2017, 101(A).

6. Grover, R. B., Integrating the function of a university to a work place to promote post-academic research. Curr. Sci., 2019, 117(7).

doi: $10.18520 / \mathrm{cs} / \mathrm{v} 118 / \mathrm{i} 8 / 1191-1195$ 